\title{
BIOSPHERE RESERVE MANAGEMENT IN ISLAMIC REPUBLIC OF IRAN: LEGAL AND REGULATED MECHANISMS
}

\author{
SHIRIN ABOLGHASEMI
}

Environment Research Station, Tehran, Iran

Proceedings of the South and Central Asian MAB Meeting of Experts on Environmental Conservation, Management and Research, Hikkaduwa, Sri Lanka 15-18 October 2002

\begin{abstract}
Summary:With its unique and invaluable biodiversity and abundant natural resources, Iran has a remarkable potential for sustainable development and growth. The Islamic Republic of Iran has established a comprehensive legislative foundation for environmental policy. Protection of the environment, enduring management of natural resources, and realization of sustainable use is provided by this body of law. These laws have been enacted on the basis of national, social and economic circumstances, and in accordance with the mandate of each sector, and its relationship to the environment. The Department of Environment as the highest national authority on environmental matters, is dedicated to monitoring of the state of the environment in the Islamic Republic of Iran.
\end{abstract}

\section{Geographical and Land Characteristics}

The Islamic Republic of Iran comprises of a land area of 1.64 million $\mathrm{km}^{2}$. It lies in the northern part of the temperate zone, between latitudes $25^{\circ} 03^{\prime}$ and $39^{\circ} 47^{\prime}$ north, and longitudes $44^{\circ} 14^{\prime}$ and $63^{\circ} 20^{\prime}$ east. The average altitude is over $1,200 \mathrm{~m}$. Iran is bordered by Turkmenistan, the Caspian (over $677 \mathrm{~km}$ of coastline), Azarbaijan, and Armenia in the north, Afghanistan and Pakistan in the east, the Persian Gulf and the Sea of Oman (over 2,300km of coastline) in the south, and Iraq and Turkey in the west.

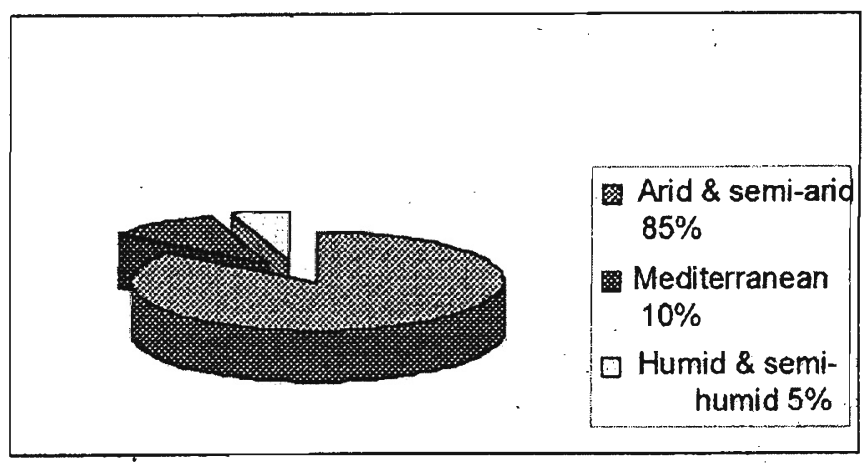

Figure 1: Main Climatic Zones of the Country (as a percentage) 
- Arid and semi-arid regions of the interior and far south, are characterized by long, warm and dry periods, sometimes lasting over seven months. These regions cover nearly $85 \%$ of the country (Figure 1 ). The annual precipitation rate in such regions varies between 30 and $250 \mathrm{~mm}$.

- The Mediterranean climate (mainly in the western Zagros mountains, the high plateau of Azerbaijan, and the Alborz mountains), is characterized by warm, dry summers, and cool damp winters, with the annual rainfall between $250 \mathrm{~mm}$ and $600 \mathrm{~mm}$. This covers about $10 \%$ of the land surface.

- Humid and semi-humid regions (mainly in the Caspian, but also in west Azarbaijan and southwest Zagros), have an annual precipitation rate between $600 \mathrm{~mm}$ and $2,000 \mathrm{~mm}$. This covers about $5 \%$ of the land surface.

The six main watersheds are: Caspian $\left(177,000 \mathrm{~km}^{2}\right)$ in the north, the Persian Gulf and the Sea of Oman $\left(430,000 \mathrm{~km}^{2}\right)$ in the south, Urumia $\left(53,000 \mathrm{~km}^{2}\right)$ in the northwest, Markazi $\left(831,000 \mathrm{~km}^{2}\right)$ in the central region, Hamoun $\left(106,000 \mathrm{~km}^{2}\right)$ in the east, and Sarakhs $\left(44,000 \mathrm{~km}^{2}\right)$ in the northeast. The total annual volume of precipitation (1970-2000) is estimated at 58,133 million $\mathrm{m}^{3}$.

\section{Institutional Arrangements for Management of Biosphere Reserves}

Article 50 of the constitution of the Islamic Republic of Iran states that:

It shall be considered a public duty in the Islamic Republic to protect the natural environment in which the present as well as future generation shall have a developing social life. Therefore, economic activities or otherwise which cause pollution or an irreparable damage to the environment shall be prohibited.

The Islamic Republic of Iran is a member of the following environmental related conventions:

- Convention on Biological Diversity (CBD).

- Convention on Wetlands (Ramsar).

- Convention on Control of Trans-boundary Movement of Hazardous Waste.

- Convention to Combat Desertification.

- Convention on International Trade in Endangered Species of Wild Fauna

- and Flora (CITES).

- United Nations Framework on Climate Change (UNFCCC).

- World Heritage Convention (WHC).

- Montreal Protocol on Ozone-layer Depletion Substances.

- Bio-Safety Protocol. 
Iran became a state member of IUCN, the World Conservation Union, in 1973, but has since suspended its membership. Moves are at hand to renew membership, now that Iran is an affiliate member of the IUCN.

The National Environmental Protection Act of 1974, following the Stockholm Conference on the Human Environment, established the Department of Environment as a Trans-Ministerial authority in the office of the Prime Minister (presently the office of the President of the Republic). The Department of Environment is thus one of the oldest and strongest environmental authorities in the country.

The Department of Environment is the focal point for environment in the Islamic Republic of Iran and acts as a secretariat to the Environment High Council. The President of the Republic is the Chairman of the Environment High Council, and the ministries of Mine and Industry, Jihad-e-Keshavarzi, Oil, Road Construction, Interior, Foreign Affairs, and Management and Planning Organization, are represented as its members. The Environment High Council is the highest environmental policy decision-making body in the Islamic Republic of Iran.

\section{The Department of Environment has as its responsibilities:}

- The establishment of a national system for ecological research, management and protection of wildlife, and the conservation of vegetation of natural resources to guarantee recreation in the area.

- The enhancement of the capacity for environment conservation of not only biological communities, but also the landscape, special habitats, and the world natural heritage, as well as the elimination of the threat to biodiversity.

- Development of criteria for selection and implementation of management plans for Biosphere Reserves.

- Establishment of a national strategy for development of recreational opportunities, especially in Biosphere Reserves.

21 Environmental Protection and Enhancement Acts, 49 Executive by-law on the Environmental Protection and Enhancement Act (approved by the Council of Ministers on 1975.02.20, with subsequent amendments thereof), 36 Air Pollution Abatement Acts (1995), 32 Executive by-law on Air Pollution Abatement Act (approved by the Council of Ministers on 1997.05.04), 36 Executive by-law on Game and Fish Law (1976), 22 Executive by-law on Prevention of Water Pollution (1994), have been enacted. 
Among the nine Iranian Biosphere Reserves, Urumieh Lake, Arjan-Parishan Wetlands, Harra Wetlands and Miankaleh Wetland are some of the important internationally recognized wetland (RAMSAR) sites.

\section{Laws, Planning and Management}

The Environmental Protection Act (1974) is the major law regarding environmental conservation in Iran. According to this Act, different categories of natural protected areas have been established in Iran, and are being administered by DoE. These sites have been carefully selected to represent all types of environments and habitats in Iran. Upto now about $7.5 \%$ of various Iranian ecosystems have been designated for conservation, and about one sixth of this has been designated as Biosphere Reserve. It is suggested that this percentage of selected ecosystems is now adequate for conservation of various ecosystems in I.R. of Iran. Legislation governing the environment declares many species of wildlife as protected, and these species are legally protected wherever they be, but this may not always be with "de facto" protection. Of course, protection is more effective within the protected areas where environmental protection guards are continuously present. The strengthening and enhancement of the management of the Department of Environment as the highest authority in the field of biodiversity conservation, has been instrumental in promoting the objectives of the nation.

The Supreme Council of Environment is a legislative body that enacts relevant regulations and decides on the classification of protected areas. The Chairman is the President of the Republic. The members of the Council comprise representstives of Jehad-e-Keshavarzi, Foreign Affairs, Mine and Industry, Interior, Health and Medical Education, Science-Technology and Research, Heads of the Department of Environment, Department of Administration and Planning (formerly Plan and Budget Organization), and the Institute of Standards and Industrial Research. There is no difference between administration entities of BRs in Islamic Republic of Iran as each Biosphere Reserve enrolled by its Directorate Bureau in places, will be controlled by the Provincial Directory and also by the National Directory. Authority for conservation of all PAs in Iran has been entrusted to the Department of Environment, which is directly under the President of the Republic. Provincial Directors of the Department of Environment have administrative control over each protected area.

The Department of Environment manages 16 national parks, 13 national natural monuments, 33 wildlife refuges and 90 protected areas (Figure 2).

92 of the most important Wetlands have been designated, comprising $3,500,000$ ha. Some of them are internationally important wetlands (21), and have been nominated as Ramsar sites (Table 1). 


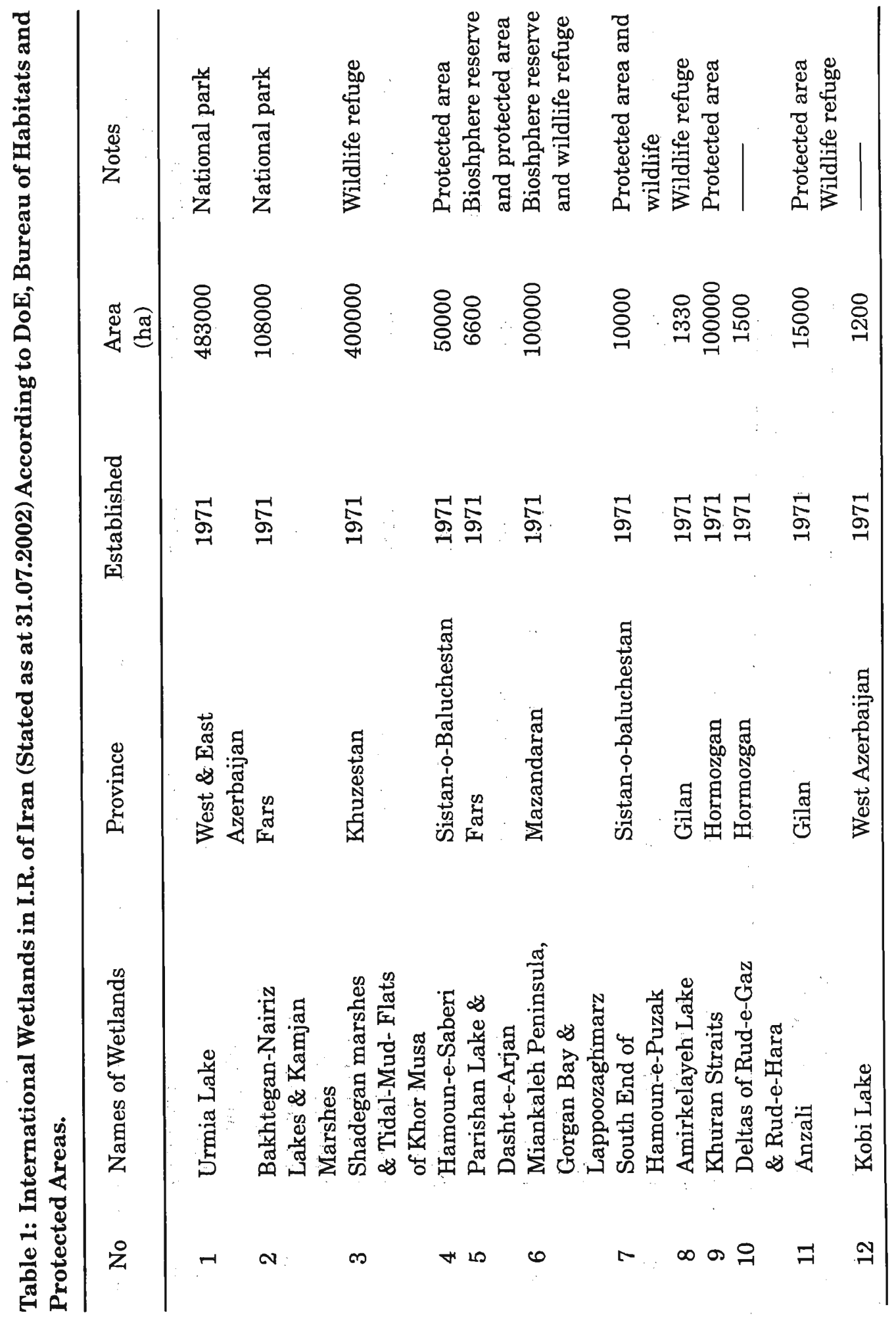




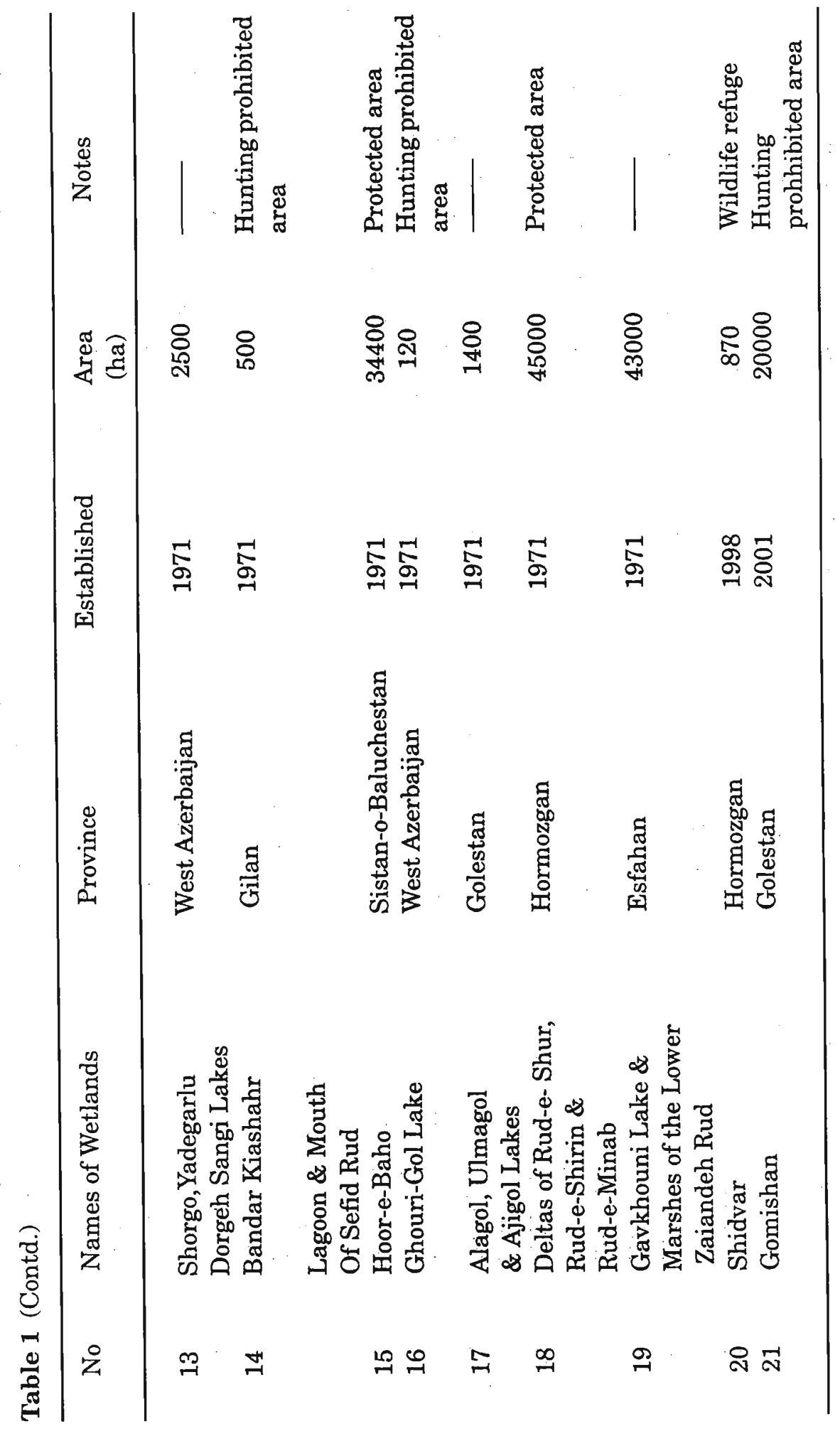




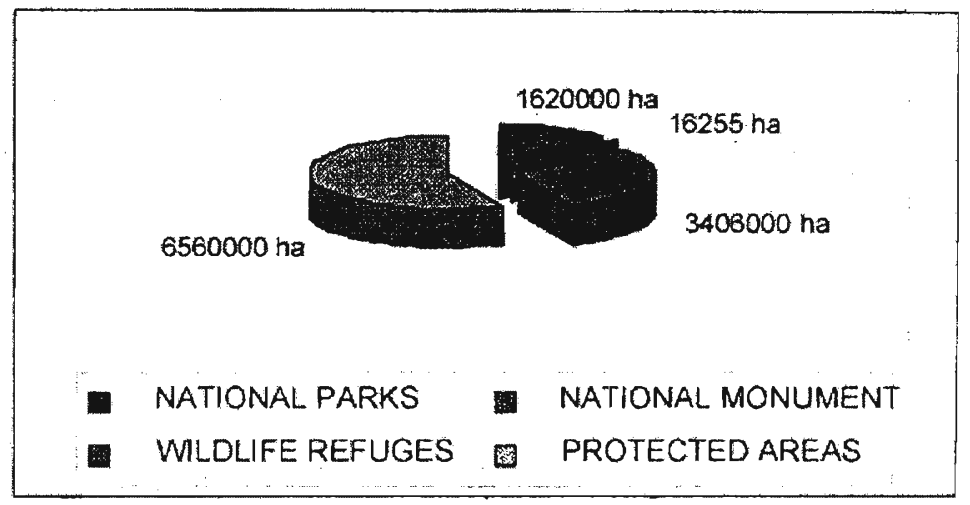

\section{Figure 2: Different Areas Managed by the Department of Environment}

Biosphere Reserves have been selected from Protected Areas. Some such as Kavir, Urumieh and Golestan have been designated National Parks (Table 2), while others (Arjan - Parishan, Geno, Harra, Touran, Miankaleh and Arasbaran) have been selected from Protected Areas (Table 3). Biosphere Reserves comprise $2,375,381$ ha of Protected Areas and cover about $1.4 \%$ of land area.

The main goal of Biosphere Reserves is to conserve biodiversity. Conservation of biodiversity supports the socioeconomic development of local communities. Although some Biosphere Reserves have been selected from among National Parks (Kavir, Urumieh, Golestan), the improvement of the quality of life of local people around the Biosphere Reserves has been well demonstrated (Table 4).

At the species level, Iran has already lost two of its most spectacular carnivores, the Persian Lion and the Caspian Tiger as a result of uncontrolled hunting and habitat destruction. In order to preserve other threatened species there is an urgent need for implementation of conservation measures (Table 5).

Biosphere Reserves of Iran have been selected from among 3 types of biome and three biogeographical provinces, so that Touran, Kavir and Geno are located in Iranian Deserts; Urumieh National Park, Golestan, Miankalehand and Arasbaran are located in Mixed Mountain. Geno, Harra Touran and Kavir belong to Iran Anatolianand deserts of Iran, while the lost have been in Iran Kaukasus mountain bio-geographical region.

Iranian habitats support some 8,500 species of plants of which almost 2,500 are endemic. There are about 10 million hectares of forest, and some 100,000 hectares of mangroves along the south border of Iran. Field studies in Iran confirm the presence of over 500 species of birds and 160 species of mammals. The wetlands of Iran are globally significant: large populations of migratory birds spend winter at these wetlands. 


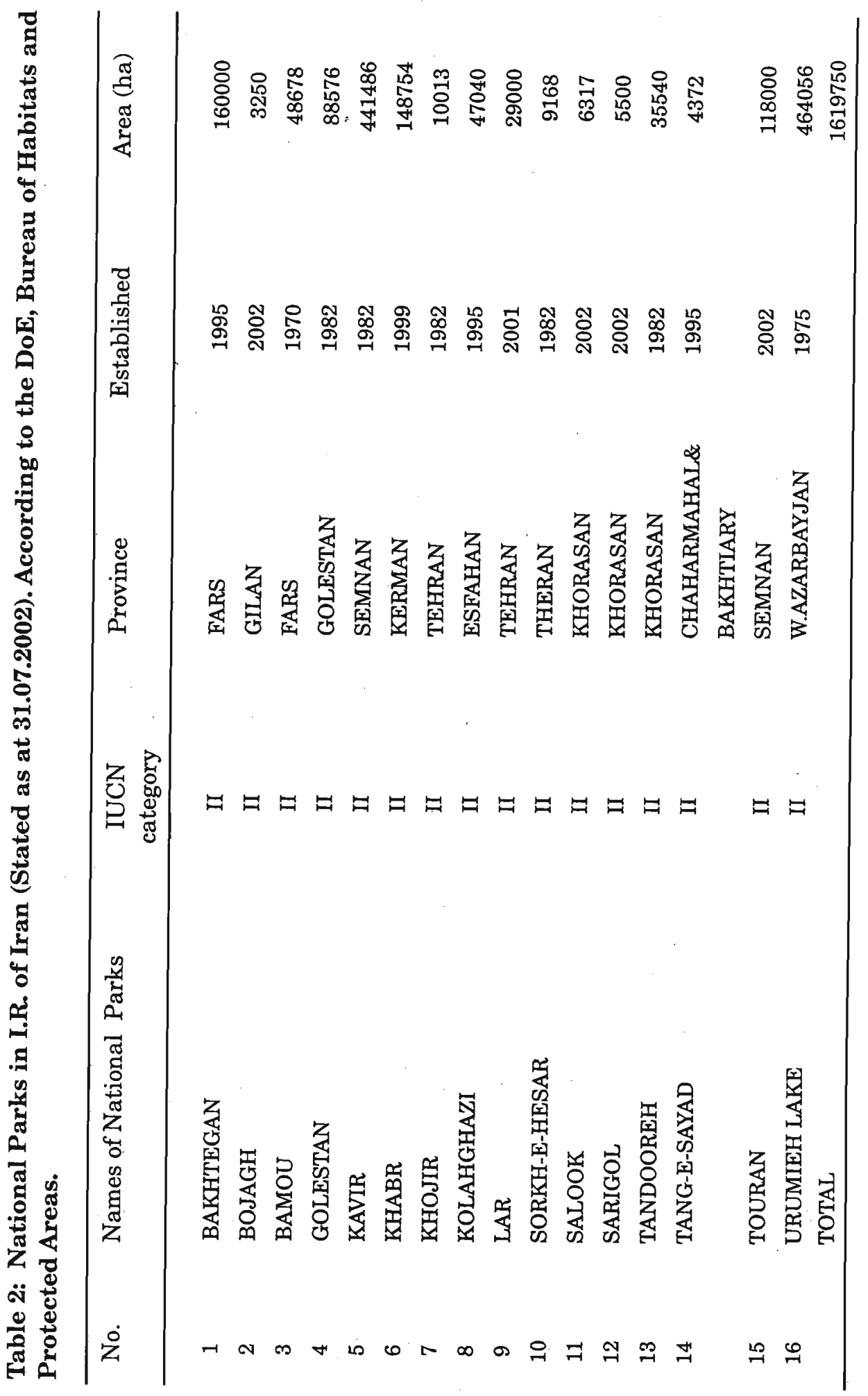




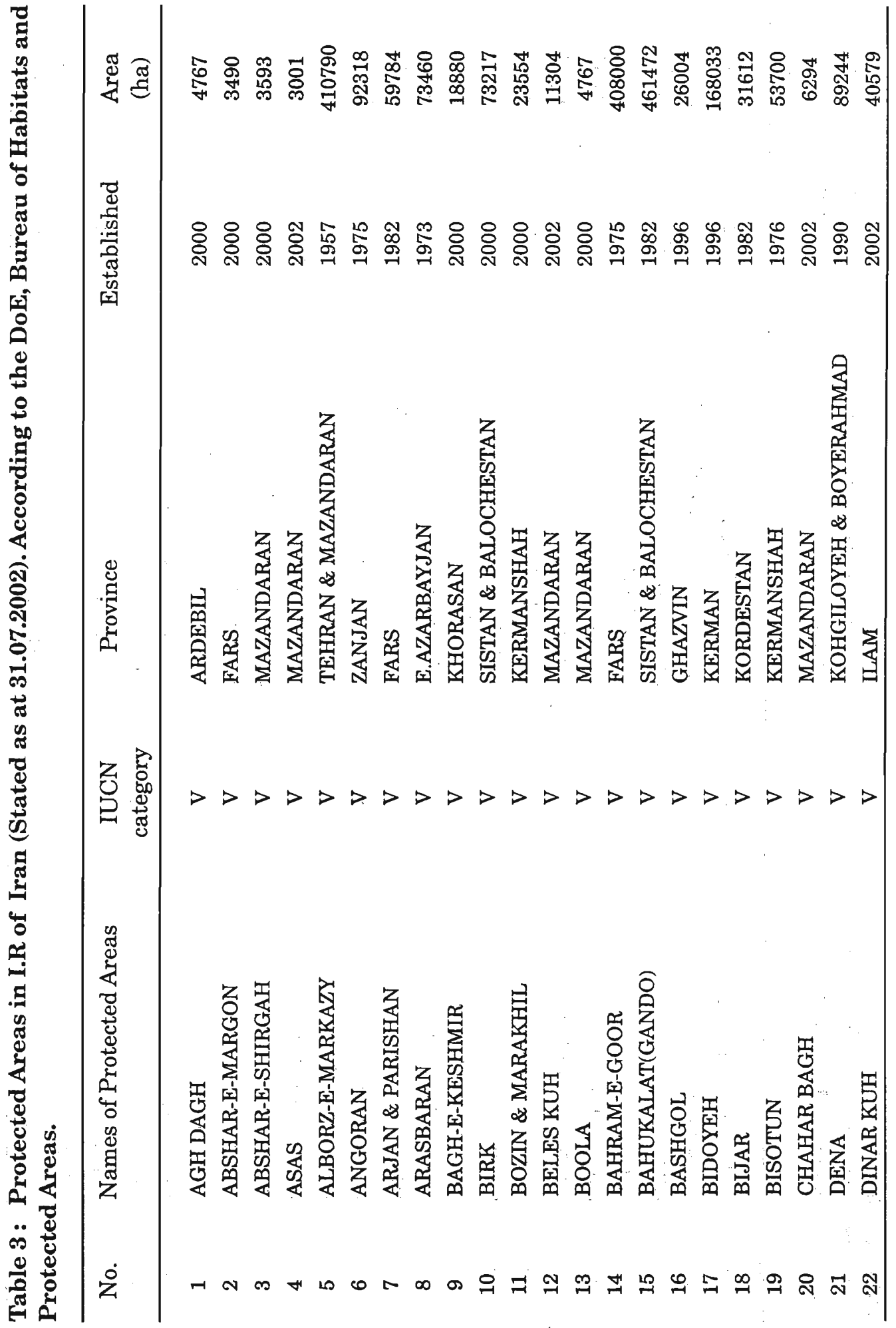




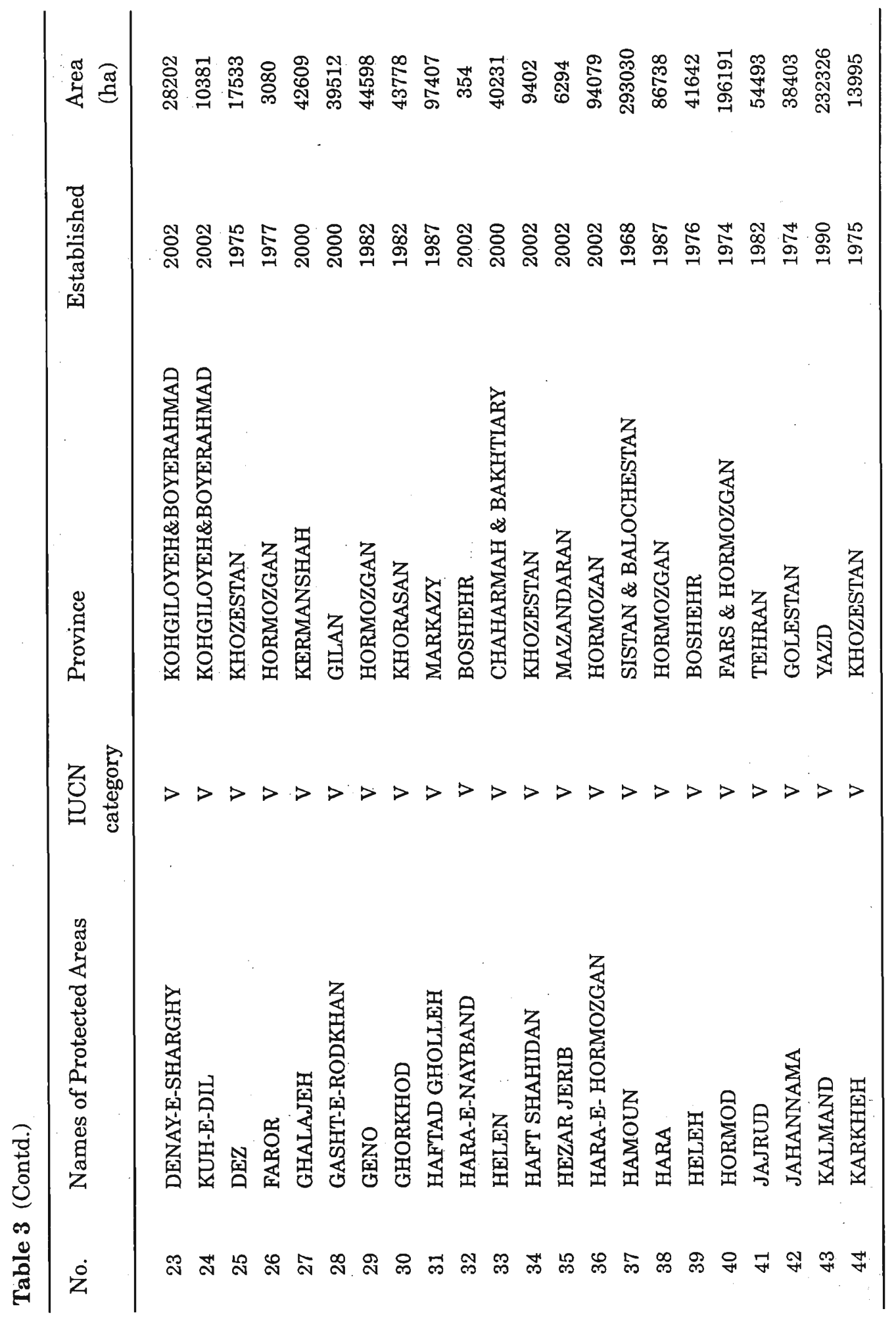




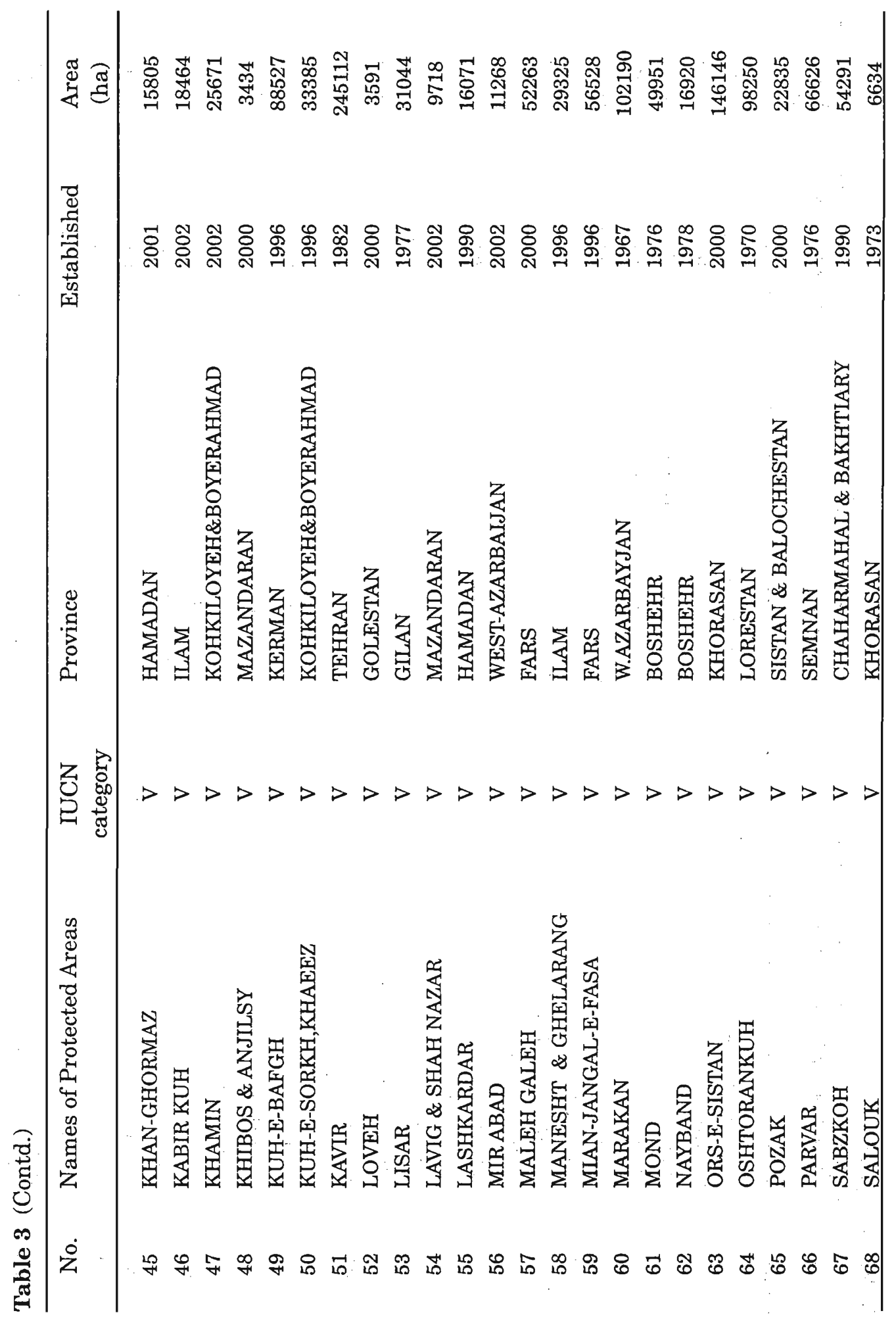




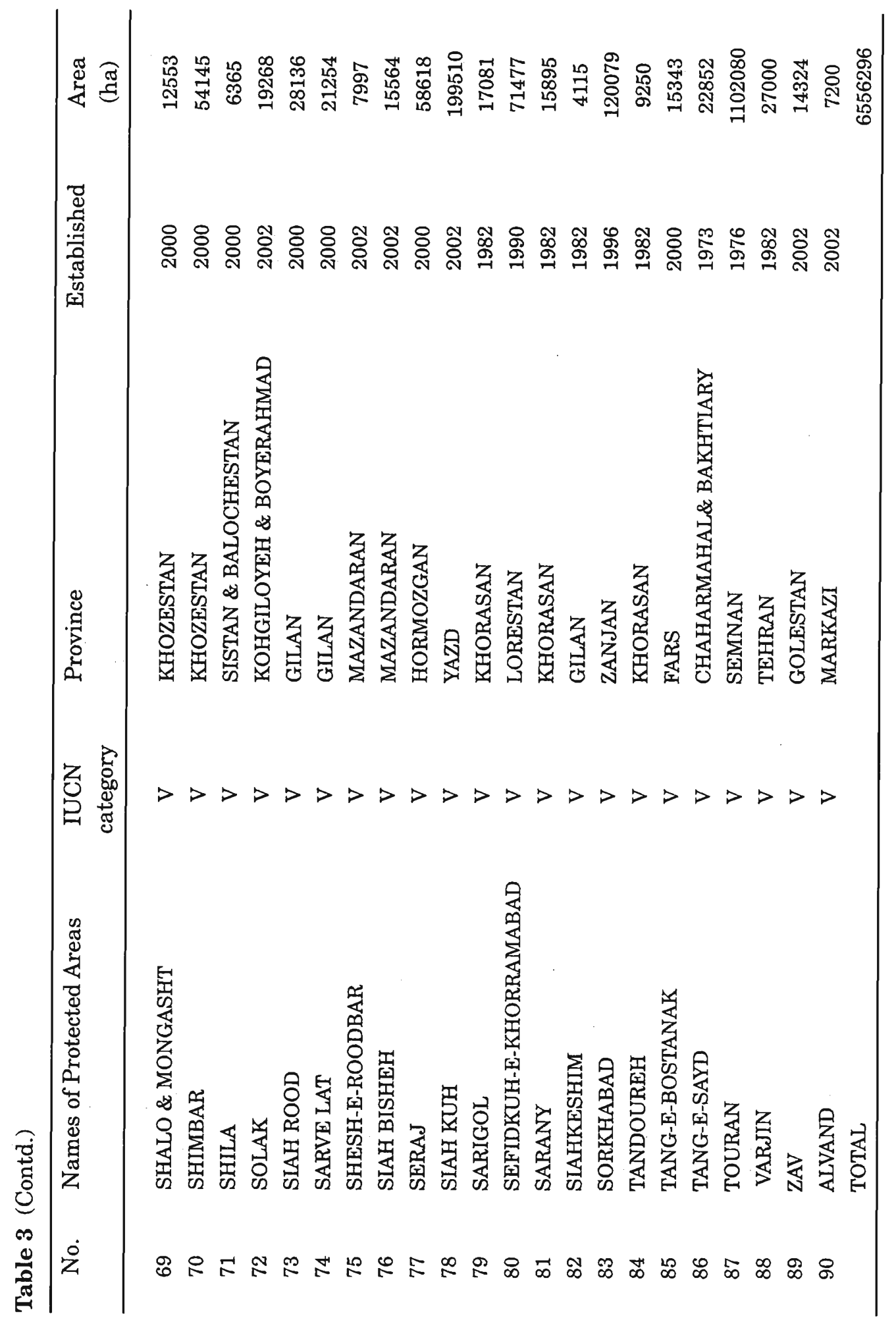




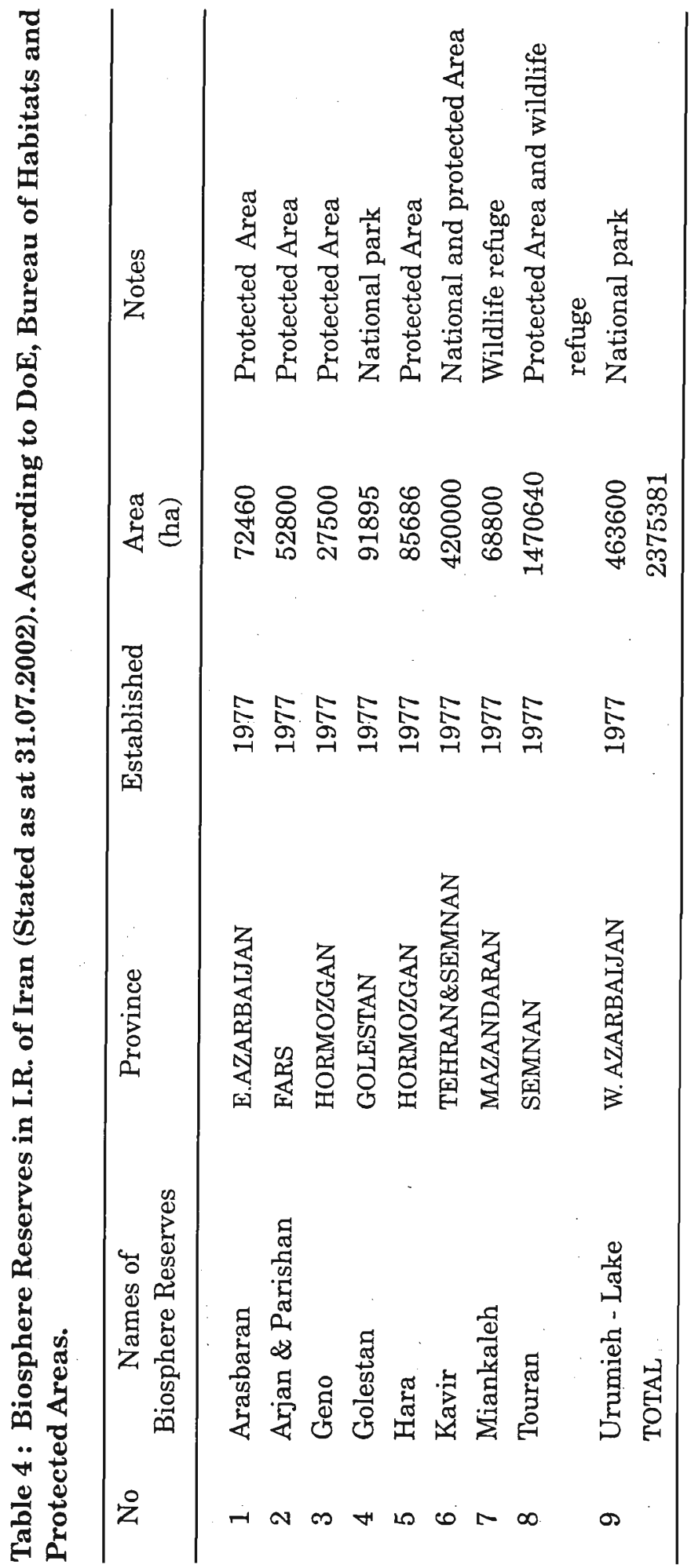




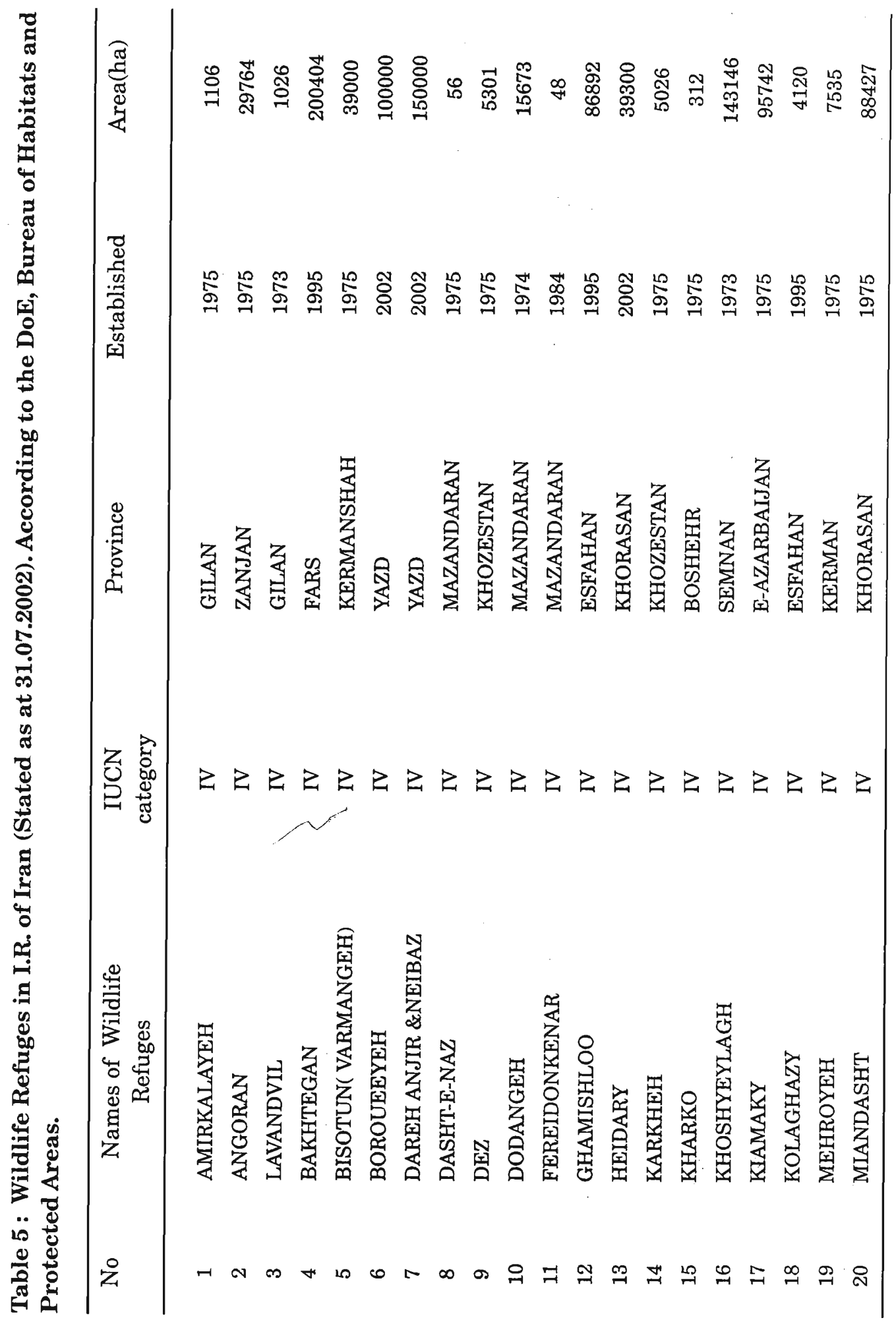




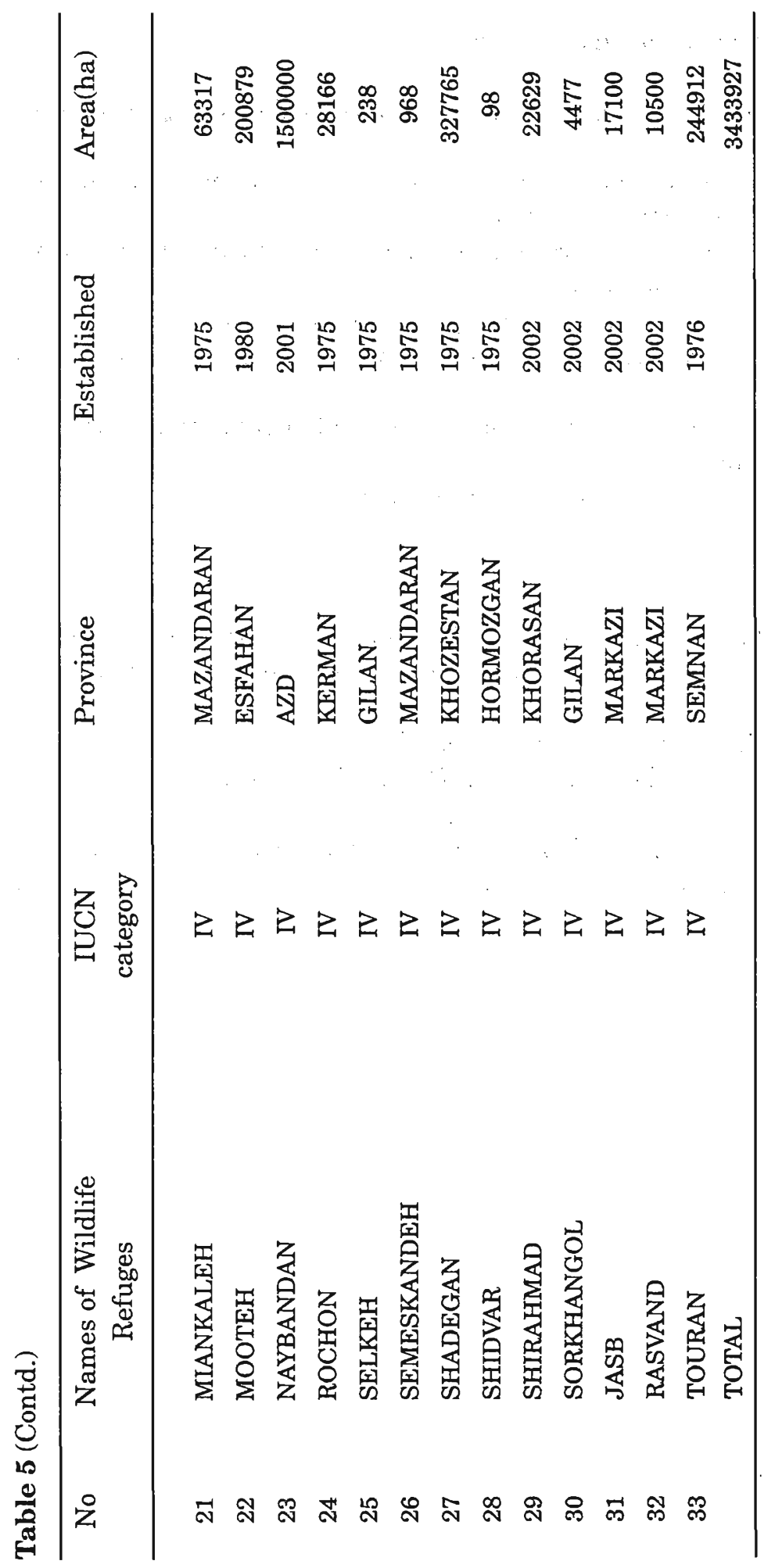


The environmental problems of Iran are as follows:

- Inadequate general knowledge of the importance of the ecological process and biodiversity.

- Lack of accessible information about the country's environmental condition.

- Inappropriate exploitation of resources.

- Production and consumption of resources in a manner which is incompatible with environmental conservation.

- Economic activities taking place at inappropriate locations.

- Lack of knowledge regarding sectoral and regional macro policies and programmes.

- Weaknesses in executing environmental acts and regulations as well as monitoring programmes.

- Lack of proper clarification with regard to policies.

\section{References}

1 Dabiri F. (1999). Environmental Code of the Islamic Republic of Iran. Bureau of legislation and parliamentarian affairs; Department of Environment.

2 Department of Environment (2000). The First National Report for the Convention on Biological Diversity 2000, NBSAP Secretariat.

3 Human Development Report of the Islamic Republic of Iran (1999). Plan \& Budget Organization and the United Nation. 